\title{
Nurse practitioner candidates: Shifting professional boundaries
}

\author{
Janet Searle, RN, MHA, Grad Dip Critical Care*
}

Emergency Department, Latrobe Regional Hospital, La Trobe University, La Trobe, Australia

Received 9 March 2007; received in revised form 3 June 2007; accepted 16 June 2007

\section{KEYWORDS \\ Nursing; \\ Nurse practitioners; \\ Rural health; \\ Emergency nursing}

\begin{abstract}
Summary
Background: In many countries the introduction of emergency nurse practitioners has been one initiative implemented by governments to address service gaps due to staff shortages: this has particularly been the case in regional and rural areas where the labour skill shortage is most acute. Even in areas where the nurse practitioner role is well established, studies have repeatedly shown enmity among health care professionals around scope of practice and work role boundaries.

Aim: The purpose of this study was to determine the impact of a new emergency nurse practitioner model of practice from the perspective of health care professionals most closely involved, and to identify the drivers and challenges to the role implementation.

Method: A descriptive exploratory survey was used to explore staff perceptions of the emergency nurse practitioner role.

Results: Participants $(N=37)$ reported that the model improved collaboration and team dynamics, aided in professionalism in nursing, improved efficiencies/quality of care, enhanced job satisfaction and affected the workload of medical staff and managers.

Participants perceived that the demand for the service was high and the Emergency Nurse Practitioner Candidates' existing qualities helped to develop the role. In addition, implementation of the role was perceived to be supported by extensive marketing, evidence-based protocols, the use of a project officer and Department of Human Services funding. Regular reviews and engagement of relevant key stakeholders was also viewed as central to the success of the role.

Challenges to the role were perceived to relate to a number of factors including: professional territorialism, limited marketing to some groups of staff, lack of access to education for the Nurse Practitioner Candidates and to some areas of supervised practice, a protracted endorsement process and lack of funding for a sustainable model.

Conclusion: Contrary to previous studies, this study showed that the majority of medical, nursing and affiliated staff strongly supported this model of practice, with little enmity evident amongst the health care professionals. Recommendations are made to help further refine the model for future practice.
\end{abstract}

(c) 2007 College of Emergency Nursing Australasia Ltd. Published by Elsevier Ltd. All rights reserved.

* Tel.: +610351738000.

E-mail address: janetsearle@yahoo.com.

1574-6267/\$ - see front matter @ 2007 College of Emergency Nursing Australasia Ltd. Published by Elsevier Ltd. All rights reserved. doi:10.1016/j.aenj.2007.06.003 


\section{Introduction}

\section{Background}

Numerous professional health care bodies argue that the inflexibility of the current contemporary workforce structure is a barrier to service delivery because of the shortages of staff to perform key roles. ${ }^{1,2}$ Data from the Australia's Health Workforce report ${ }^{3}$ demonstrates that the medical and allied health population drops significantly outside metropolitan areas, whereas nurses provide the most stable consistent workforce (see Fig. 1). Duckett ${ }^{4}$ explains that transient team members may not be fully aware of the local resources and make inappropriate referrals or consultative decisions. Utilising the more stable workforce members to do certain tasks normally undertaken by other health care professionals will assist with meeting service gaps and improve service delivery to patients.

The Department of Human Services (DHS) in Victoria initiated Phase One of the Nurse Practitioner Project in 1999, with a view to address skill mix shortages, increase workforce flexibility and improve service delivery to patients. This new role extends outside the Victorian Registered Nurses' legislation in five main areas; prescribing medications, initiating diagnostic imaging and pathology testing, approving absence from work certificates, referring to specialists and admitting and discharging consumers. The Nurses Board of Victoria requires these extensions to practice to be supported by evidence-based Clinical Practice Guidelines (CPGs) developed by the Nurse Practitioner Candidate. A collaborative endorsement process is undertaken for each CPG developed with multidisciplinary key stakeholders before final approval is given by the quality committee, pharmacy committee and then the Executive of the organisation. Nurses working towards a nurse practitioner position in Victoria are termed 'candidates' and have limitations to the extensions to practice, such as no prescribing rights, until endorsed by the Nurses Board of Victoria. The Emergency Nurse Practitioner Candidate (ENPC) title is particular to Victoria, other jurisdictions and/or states may use other titles. Emergency Nurse Practitioner Candidate will be used to describe the nurse practitioner candidate within this article.
There is already evidence in the literature that clearly demonstrates the positive impact nurse practitioners have on emergency department (ED) systems, patients' satisfaction and health outcomes. These include improved waiting times, convenience of services for patients and carers, as well as enhancing health care delivery and producing quality outcomes. ${ }^{5-9}$ However, even in areas where this role is well established, previous studies have shown there is still resistance to the role, fears of doctors being replaced, enmity between the health care professionals (HCPs) and disagreement on role boundaries. ${ }^{2,9-17}$ The shift of skill mix from one profession to the other impacts on all HCPs involved. $4,18,19$ There are limited qualitative studies in Australia that have explored the impact of ENPC implementation on other HCPs.

\section{Setting}

This study was based at a regional referral hospital 150 kilometres east of Melbourne, Victoria. The ED has 14 beds with an additional four-bed short stay unit and treats approximately 25,000 patients per year. Seventy-one percent (\%) of patients in the 2004/2005 financial year were Australasian Triage Scale categories 4 and 5, indicating the majority of presentations were for minor illnesses and injuries. The ED is staffed by seven nurses, three resident doctors during the day, termed Hospital Medical Officers (HMOs) who rotate quarterly as part of their resident training program, and one ED Physician to supervise the department.

The ENPCs were first introduced in October 2005 as part of a DHS funded project. Two candidates share the one full-time equivalent position. They are provided with a medical mentor each shift and work in a supernumerary role. A project officer was employed part-time for the first 12 months to plan, implement and evaluate the role and a steering committee was established to provide governance, direction and support. Extensive consultation, education and marketing sessions were conducted with ED staff, hospital staff, consumers and other key stakeholders by the project officer prior to and during the ENPC implementation.

Both the project officer and ENPCs organised numerous education strategies, prior to and during the ENPCs implementation in order to meet their education and credentialling requirements. Existing educational programs at the regional hospital were utilised and an affiliation devel-

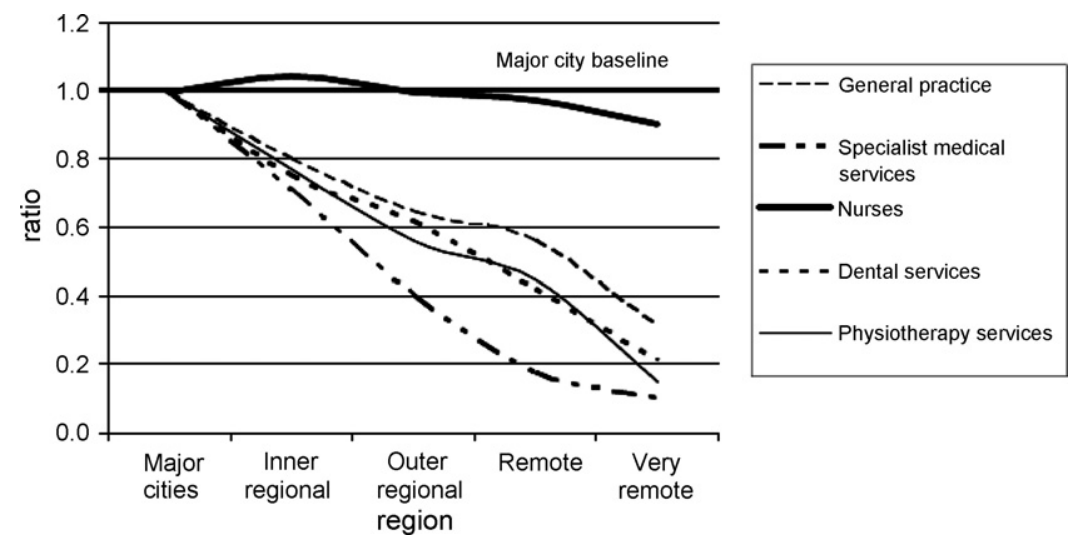

Figure 1 Practitioner to population ratios by area. Source: Australian Health Workforce Commission Report, 2005, p. 2733. 
oped with the local university's School of Rural Health and the HMOs training program. This approach fostered collegial relationships between different divisions of the organisation and the ENPCs. They also attended monthly Victorian Emergency Nurse Practitioner Collaborative study days, as well as additional clinical supernumerary time at metropolitan tertiary referral centres and in local general practitioner clinics.

The project was continually evaluated throughout the first year, with quarterly reviews on performance data, as well as two staff surveys and a patient satisfaction survey being conducted.

\section{Aim}

The aim of this study was to:

1. Determine the impact of the ENPC role and model of practice from the perspectives of nursing, medical and allied health staff.
2. Identify the drivers and challenges to the role implementation from the perspectives of nursing, medical and allied health staff.

3. Make recommendations arising from the analysis to assist in refining this new model of care for future practice.

\section{Method}

\section{Design}

This study was conducted in accordance with the Australian National Health and Medical Research Foundation's National Statement on the Ethical Conduct of research involving Humans. ${ }^{20}$ Approval was given by the La Trobe Regional Hospital Human and Research Ethics Committee (HREC) and the La Trobe University Faculty of Health Ethics Committee (FHEC). ${ }^{21}$

A semi-structured self reporting questionnaire was distributed 10 months after the introduction of ENPCs to explore staff perceptions of the ENPC role. The question-

\section{Employment Characteristics}

Please select one of the following categories that best describes your level of appointment.

Nursing $\square \quad$ Medical $\square \quad$ Other $\square$

Years of Experience in role:

Age

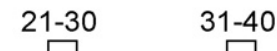

$41-50$

$51-60$

$61-70$

Gender:

$$
\text { Male }
$$

Female

1. Have you worked with Nurse Practitioners before?

- If yes, what practice setting or health service location was it in?

2. Do you think there is a need for an Emergency Nurse Practitioner Candidate (ENPC) in the ED?

(a) If no, why?

3. (a) What do you perceive to be the benefits of having an ENPC in this ED?

(b) What facilitating factors/drivers have helped with the ENPC role implementation?

(c) Of these, which ones do you think should be encouraged to further integrate ENPCs into ED?

4. (a) What are the disadvantages of having an ENPC in the ED?

(b) Are there any barriers that you see inhibiting the development of the ENPC role?

(c) If yes, can you suggest ways to overcome these?

5. How has the ENPC affected your own role?

6. Have you met any resistance to the ENPC role implementation?

7. Has your job satisfaction changed since the introduction of ENPCs? (a) If yes, how?

8. Have you noticed any change in the relationships within the ED team since the introduction of ENPCs?

(a) If yes, how?

9. Have you any further comments on the future direction for the ENPC role in the ED?

Figure 2 Impact of Emergency Nurse Practitioners on the Workforce Questionnaire. 
naire was developed based on the literature review, with open-ended core questions for a consistent approach. ${ }^{22,23}$ Both the La Trobe University FHEC and the Regional Hospital HREC approved the questionnaire. A total of nine questions (see Fig. 2) focussed on the impact the ENPC had on the HCP's own role as well as drivers and challenges to the role implementation.

Staff attitudes are just one of the issues that need to be considered during ENPC implementation. Other outcomes were also measured, such as performance data on waiting times, patients' length of stay, patient satisfaction, appropriateness of care on the ENPCs clinical log, and competency assessments on clinical skills and CPG management, however, these other outcomes are beyond the scope of this paper.

\section{Procedure}

The questionnaires were distributed during August 2006 in order to establish an accurate view of the service at a specific point in time. Follow-up reminders were given at staff meetings and entered in the staff communication books.

\section{Participants}

Potential participants for this study were drawn from a total population of $80 \mathrm{HCPs}$, and included:

- 11 of 11 ED consultants (100\%);

- 19 of 20 ED HMOs (95\%);

- 38 of 41 ED nursing staff (93\%), which included the ENPCs;

- Department Heads of Pharmacy (1), Radiology (1) and Pathology (1);

- Specialist doctors who receive referrals from the ENPCs:

- 1 of 1 orthopaedic registrar (100\%);

- 2 of 2 surgical registrars $(100 \%)$;

- 3 of 3 medical registrars (100\%);

- 3 of 3 paediatric registrars/HMOs (100\%).

Staff on leave during the time of data collection were excluded to optimise the response rate.

\section{Ethical considerations}

Due to the small sample from affiliated departments, the questionnaire requested participants to indicate their employment characteristics as medical, nursing or other, to remove the possibility of identifying participants.

An independent staff member distributed the questionnaire with a participant information sheet to prevent any potential coercion or bias in the sample. The name and contact details of the researcher were included in accordance with the National Statement on Ethical Conduct in Research Involving Humans. ${ }^{20}$ This may have affected participant's choice on whether or not to participate in the study.

Instructions on the participant information sheet outlined that the surveys were not coded and were returned to the researcher in a sealed envelope via either internal mail or in a sealed box set up in the ED tea room, to ensure anonymity and confidentiality. A returned completed survey implied that consent was given.

\section{Limitations}

Even though the overall response rate was $46 \%(N=37)$ and data saturation was reached, the researcher acknowledges that those staff who did not return the survey may not support this model of practice. Obtaining responses from a representative sample and gathering in-depth data are limitations when conducting qualitative surveys. ${ }^{23}$

\section{Data analysis}

A qualitative thematic analysis of the data was undertaken, using the method outlined by Polit and Becks. ${ }^{24}$ Common themes were identified according to impact on the workforce, drivers and challenges to the role implementation, each of these had several subcategories. Data was transcribed by the researcher into tables using Microsoft ${ }^{\circledR}$ Word, ensuring that the demographic data remained with each subcategory. Once similarities and differences were identified in each subcategory, the concepts became more defined. These were then compared with demographic data and then between professional groups, in order to achieve a refined analysis. The researcher checked the auditability of the thematic analysis retrospectively.

\section{Results}

A total of $49 \%(n=19)$ of medical staff, $42 \%(n=16)$ of nursing staff and $67 \%(n=2)$ of affiliated staff completed the questionnaires. The main themes that emerged from the analysis are outlined below, with short extracts from the surveys used to illustrate points raised.

\section{Impact on workforce}

The main themes were:

- improved collaboration and team dynamics;

- aids professionalism in nursing;

- improved efficiencies/quality of care;

- effect on job satisfaction;

- impact on managerial duties;

- impact on doctors workload.

\section{Improved collaboration and team dynamics}

A central theme that emerged from the surveys was improved collaboration between doctors and nurses, amongst the nursing team itself, aided better liaison between the ED and other departments as well as improved communication to patients. The medical staff commented there was now "less us versus them" attitude, and noted an improved rapport and communication between the two teams, whilst others also identified that it has aided in bridging the gap between doctors and nurses. Senior medical staff felt that patients were referred onto specialists quicker under ENPC management. One nurse wrote: "the introduction of the ENPCs has been a positive step forward 
in providing extra support to the medical/nursing staff and has created a stronger unity between nurse/doctor relationships'.

Nurses remarked on improved communication to clients as the ENPCs provided invaluable patient education to the non-urgent patients, which HMOs did not always have the time to do. Some nurses also outlined that they found the ENPCs to be more approachable than HMOs. Participants from affiliated departments felt they now have "better liaison between ED and other departments" since the introduction of ENPCs. One doctor noted however, that he observed an incident where there was "increased difficulty/tension when an ENPC asks other nursing staff to perform a nursing duty on their patient'.

\section{Aids professionalism in nursing}

The ENPC role was seen as a very positive initiative from a nursing perspective. Comments included; they have proven to be an asset to the department, as they "are an immense advantage", were seen as "positive role models... and extremely beneficial to the ED'" whilst providing a consistent stable workforce, due to "continuity of staffing. Doctors come and go, nurses stay, so skills stay'. The increased autonomy and expansion of the role were seen to provide better career opportunities, aiding in staff retention and recruitment in the future.

Registered nurses saw the ENPCs as a good resource, as their knowledge base was excellent and clinical expertise helped other staff members. The nurses highlighted that their own knowledge base and participation in procedures had improved from the ENPCs sharing their clinical expertise and knowledge.

\section{Improved efficiencies/quality of care}

There was considerable comment on the improved efficiencies this model of practice had on the ED and staff workload. A total of $50 \%(n=8)$ of nurses identified that patients' waiting times, quality of care, flow through the department, satisfaction and discharge education had improved, thus enhancing patient outcomes.

Medical staff commented that the ENPCs have had the training to make cost effective decisions quickly and appropriately, and have better skills and relevant local knowledge than most HMOs. Twenty-one percent $(n=4)$ of doctors felt ENPCs greatly assisted their own role by improving patient flow with reduced time for procedures/consultation, faster referral of patients and improved patient management and waiting times.

The ENPC role was also seen as an additional resource for HCPs in several aspects. Medical and nursing staff outlined that the ENPCs assisted in not only educating junior nurses, but also junior HMOs. Participants also commented that the transfer of certain skills onto nurses helped meet service gaps, as some of the junior HMO's procedural skills were limited. The ENPCs role expansion to "perform time consuming procedures, such as suturing and plastering" relieved the patient load on medical staff and allowed them to be more available to manage the acute patients.
Job satisfaction

Overall, $42 \%(n=8)$ of medical and $56 \%(n=9)$ of nursing staff stated that their job satisfaction had increased, due to patient flow improving, increased patient satisfaction, less complaints and improved collaboration between the HMOs and nurses. Both recognised there was less pressure on doctors and that ENPCs had reduced both medical and nursing workload. Contrary to one of the doctor's comments mentioned previously, nurses added that the ENPCs performed tasks such as blood tests, taking vital signs and inserting intravenous cannulas that HMOs would not do on their patients, which eased the workload of nurses and improved their job satisfaction.

Only $5 \%(n=1)$ of medical staff felt their job satisfaction had decreased, due to less exposure to managing patients with minor illnesses and injuries. The remaining participants made no comment.

\section{Impact on managerial duties}

One registered nurse and one HCP from an affiliated department outlined that their managerial duties had increased due to the time required to review and approve the ENPCs clinical practice guidelines.

Whilst only $10 \%(n=2)$ of the senior doctors felt that their managerial duties had increased, $16 \% \quad(n=3)$ of other senior medical staff outlined that their supervision duties had decreased, stating the ENPCs were "easier to teach/delegate and supervise" and they have "made life easier when they are on regarding supervising ED treatment and team.' The remaining medical staff had no comment.

\section{Impact on doctors' workload}

A decrease in workload was noted by $58 \%(n=11)$ of medical staff "as the ENPCs see quite a significant amount of patients when on duty." Several medical and nursing participants highlighted that the ENPCs help relieve pressure on the HMOs as this model allows them to be more available to manage the acute patients. One doctor however, felt his workload had increased due to prescribing scripts on behalf of the ENPC.

\section{Drivers}

The main drivers to the ENPC role implementation were identified as:

- demand for service;

- ENPCs existing qualities;

- extensive marketing;

- solid protocols;

- use of project officer and DHS funding;

- regular reviews;

- ED management, medical and nursing support;

- executive commitment.

A total of $95 \%(n=18)$ of the medical staff and $100 \%$ $(n=16)$ of the nurses and other HCPs surveyed felt that there was a definite need for this model of practice. The high HMO turnover and their variability of skills also raised some nursing staff's awareness to the need for ENPCs. One doctor felt that there were enough HMOs who "can see all 
types of patients, but the ENPCs can just see quick and easy patients, leaving all complicated patients to HMOs. If they take a place for one HMO, they increase the load of work for other HMOs."

Both medical and nursing participants identified the ENPCs existing qualities had facilitated the implementation of this new role. Comments included that the two candidates were very enthusiastic "personalities helps greatly" and that their already established rapport with other HCPs and vast local knowledge were a great advantage. "Having staff committed to the role" and "previously knowing the candidates" 'were also seen as positive drivers.

Participants acknowledged that the marketing and education sessions provided helped them to understand the ENPCs scope of practice, role boundaries and how the ENPCs fitted into the ED team. One staff member from an affiliated department felt the development of the ENPCs CPGs aided them to better understand in defining this new role and scope of practice.

The regular reviews on the internal evaluation regarding feasibility, improved access, was evidenced-based and an appropriate service was identified by some senior medical staff as a driver, as this aided in determining the need and efficiency of this service.

Twenty-one percent $(n=4)$ of medical staff and $56 \%(n=9)$ of nursing staff identified the support from ED management and executive as a facilitating factor. Staff in affiliated departments outlined that the "education input from outside service providers" also aided the role implementation. Forty-seven percent $(n=9)$ of medical and $31 \%(n=5)$ of nursing staff made no comments or wrote "don't know" to the drivers of the ENPC role implementation.

\section{Challenges}

Challenges to the role implementation identified from participants included:

- professional territorialism;

- marketing to all staff;

- access to education;

- access to supervised practice for ENPCs;

- staffing issues;

- sustainability and funding;

- protracted endorsement process.

Whilst nearly three-quarters of participants felt that there was no resistance to the ENPC role when asked directly (see Table 1), some did identify a small degree of enmity from medical staff when answering the question, 'What where the barriers that you see inhibiting the development of this role?' Ten percent $(n=2)$ of medical, $38 \%(n=6)$ of nurses and one staff member from an affiliated department outlined that they noted "resistance from medical practitioners-turf wars" the "threat to HMO positions" and "resistance from some registrars." In addition, 10\% $(n=2)$ of medical and $12.5 \%(n=2)$ of nursing staff noted some patient resistance when treated by an ENPC. Comments included a "minority of patients will still want to see a doctor" and "there is always the patient who wants to be treated by the professor."

Capturing all staff for marketing and education was identified by $5 \%(n=1)$ of medical and $6 \%(n=1)$ of nursing staff as a challenge, due to the rotation of rosters and $\mathrm{HMO}$ staff turnover. The geographical distance for the ENPCs to travel to the metropolitan area for education, study days and to spend supernumerary time in specialised tertiary referral EDs was identified as a challenge. Participants also highlighted the limited availability of the ED physician to supervise the ENPCs practice, as the one physician on duty also had to supervise the HMOs.

Only $6 \%(n=1)$ of nursing staff noted that utilising the existing senior nurses to fulfil the ENPC role created nursing staff shortages, and occasionally the ENPC was removed from their role to assist with shortfalls in the nursing roster.

Nineteen percent $(n=3)$ of nursing and $5 \%(n=1)$ of medical staff questioned the ongoing sustainability of this role once the DHS funding ended. One senior doctor outlined that if the ENPC position was "to replace current medical staffing, I would not be supportive."

Six percent $(n=1)$ of nursing staff outlined that the protracted endorsement process was a main challenge to the role development. Similarly, $16 \%(n=3)$ of medical staff identified the ENPCs current limitations to no prescribing rights as a barrier, which consequently increased doctors' workload. Contrary to the majority of participants, $5 \%(n=1)$ of medical and $13 \%(n=2)$ of nursing staff felt there was lack of support from senior medical and executive staff, whilst one doctor felt that the ED was over-staffed with this model of practice.

\section{Discussion}

This study adds to previous findings in the literature that this model of practice has significantly increased staff's job satisfaction, whilst reinforcing some of the outcomes in earlier work, such as improved efficiencies, quality of care and aiding professionalism in nursing. However, contrary to the literature, this study also shows improved collaboration and team dynamics across multidisciplinary teams and illustrates

Table 1 Participants response to 'Have you met resistance to the ENPC role implementation? $(N=37)$

\begin{tabular}{lcllc}
\hline & Medical $n(\%)$ & Nursing $n(\%)$ & Others $n(\%)$ & Total $n(\%)$ \\
\hline No comments & $4(21 \%)$ & 0 & 0 & $4(11 \%)$ \\
Medical resistance & $2(11 \%)$ & $2(12.5 \%)$ & 0 & $4(11 \%)$ \\
Nursing resistance & 0 & $2(12.5 \%)$ & 0 & 0 \\
Patient resistance & 0 & $12(75 \%)$ & 0 & $2(5 \%)$ \\
No resistance & $13(68 \%)$ & & $2(100 \%)$ & $27(73 \%)$ \\
\hline
\end{tabular}


that the ENPCs were well received by the majority of HCPs most closely involved. Factors that could have contributed to this are the demand for service, high turnover of HMOs, extensive marketing, the ENPCs existing qualities and the support from management. A comparison study to a similar demographic region and in a metropolitan area will determine if the location of this new service has contributed to the success of the role.

The effect this model of practice had on other HCP's actual workload varied. Managers of each department and some senior doctors outlined that their workload had initially increased due to reviewing and approving CPGs, assisting with the ENPCs educational needs, supervising clinical practice and writing scripts on their behalf. However, these issues will subside once the ENPC role is more established and even be abated once the candidates are endorsed. Only $26 \%(n=5)$ of all medical staff commented on the impact on their managerial duties. This maybe due to the small number of managers (who were de-identified in the surveys) and the open-ended style question which did not specifically ask participants to directly comment on managerial duties.

The impact on HMOs in the ED has been the most significant. The majority of HMOs felt that their workload had decreased, which was also recognised by the nurses. However, one doctor highlighted that his exposure to minor illnesses and injuries was limited when the ENPCs were on duty. As this is a collaborative model, patients do not wait exclusively for ENPC treatment and management from triage. Education on of this model of practice may help alleviate this barrier. Some medical staff did identify the lack of knowledge about the ENPC role as a challenge, and requested further education sessions to overcome this and thus further increase medical acceptance to the role.

Some participants questioned the feasibility of this role. Evidence in the literature has shown that the high turnover of doctors in the workforce hinders the department's efficiency with the burden of familiarising new staff with local processes. ${ }^{25}$ The nurses are the only profession that provide a stable workforce in regional/rural areas, ${ }^{3}$ giving more stability and support to senior medical staff, lessening the disruption created by rotation of doctors in training and the unevenness in the availability and skill levels. ${ }^{25}$ Utilising nurses to perform other skills normally conducted by doctors is only logical in meeting the service gaps in the regional/rural area.

Careful consideration needs to be given to the type of quantitative data used to evaluate this role. Directly comparing the efficiency of one HCP to another may build upon an assumption that the ENPC is more efficient, fear that HMOs may loose a position and increase the risk of causing enmity and resistance to the ENPC role. ${ }^{26}$ In addition, common methodological issues such as variable triage categories and nature of presenting problems significantly limits the conclusions that may be drawn from this data. ${ }^{27}$ Evaluation should, therefore, be based on a more holistic method which will foster a collaborative approach to this new model of care.

The drivers and challenges identified will assist in refining this model of practice. Extensive education and marketing to staff members and the community will continue to raise awareness that the ENPCs meet certain educational and credentialing standards. Recognising that this model of practice is aimed at being a collaborative one will eliminate the infinitesimal amount of fears found in this study of loosing an $\mathrm{HMO}$ position, professional territorialism, and patient resistance as well as continue to prevent confusion on role boundaries and scope of practice.

Access to education has been addressed to some extent by utilising local resources. The hospital developed an affiliation with the local university, the HMO teaching program and local general practitioners. Emergency Nurse Practitioner Candidates attend education sessions as appropriate to their learning needs. Not all of their education and credentialing needs are available locally, however, and the ENPCs are still required at times to travel to the metropoli$\tan$ area. Teleconferencing is an option, but cost is an inhibiting factor. This, therefore, remains a challenge and may detract future ENPCs from the role. A formal restructure in the local education resources to incorporate a more multidisciplinary focus will not only assist in addressing this barrier, but also provide greater emphasis on teamwork and inter-professional issues. ${ }^{4}$

The concern that this model of practice removes the senior nursing staff away from the traditional nursing staff base is a valid one. This initiative will not be beneficial if there is also a nursing shortage in the department, as it will then be only shifting the problem. ${ }^{2}$

Executive and ED management support assures the continued sustainability and funding of the ENPC role. As the project officer's role was only for the first 12 months, management need to continually evaluate the working relationships within the ED team and with affiliated departments to ensure the continued success of this role. The hospital is currently exploring the option of developing ENPC review clinics to assist with meeting local service gaps and aid the sustainability and funding for this role in the future.

The perceived protracted endorsement process is an issue for the Nurses Board of Victoria and falls outside the scope of this study.

\section{Recommendations for future practice}

- continue extensive marketing strategies to staff and community;

- continued management and executive support;

- ongoing regular evaluation and feedback to staff;

- explore options of nurse practitioner review clinics;

- formally restructure local educational resources to incorporate a more multidisciplinary focus.

This study is the first found in regional Victoria on the impact this model of practice has on other HCPs. A study to compare these results with a metropolitan setting would be beneficial to determine if the tide is finally turning on the acceptance of this role.

\section{Conclusion}

Although existing professional roles have served the delivery of health care well in the past, the changing demographics of the workforce has resulted in less HCPs in regional and rural areas. As nurses are the most consistent stable workforce 
in regional areas, it is only logical that they are used to address the current service gaps. As seen in the literature, the transfer of skill mix from medical to nursing, however, significantly impacts on all HCPs.

This study showed that there was wide acceptance of the ENPC role in the regional ED, however, some of the barriers demonstrated in the literature do exist at the local level. The infinitesimal enmity between HCPs and professional territorialism found can be overcome with persistent ongoing education and marketing strategies. Albeit, contrary to previous studies, the impact of ENPCs on the local workforce was generally seen as a positive one, with improved efficiencies, increased staff satisfaction, improved collaboration and aiding in the professionalism of nursing. The need for ongoing evaluation of effectiveness whilst paying attention to the impact on all members of the health care team is paramount to the continued success of the emergency nurse practitioner model of practice.

\section{Competing Interests}

None declared by the author.

\section{Funding}

None declared by the author.

\section{References}

1. Duckett S, Kenny A. A question of place: Medical power in rural Australia. Soc Sci Med 2004;58(6):1059-73.

2. Buchan J, Calman L, Skill-mix and policy change in the health workforce: Nurses in advanced roles. OECD Health Working Papers No. 17; 2005 [cited April 1, 2006]. Available from: http://www.oecd.org/dataoecd/30/28/33857785.pdf.

3. Productivity Commission. Australia's Health Workforce. Productivity Commission Research Report; 2005 [cited April 1, 2006]. Available from: http://www.pc.gov.au/study/ healthworkforce/finalreport/healthworkforce.pdf.

4. Duckett SJ. Health workforce design for the 21st century. Aust Health Rev 2005;29(2):201-10.

5. Barr M, Johnston D, McConnell D. Patient satisfaction with a new nurse practitioner service. Accid Emerg Nurs 2000;8(3):144-7.

6. Byrne G, Richardson M, Brunsdon J, Patel A. An evaluation of the care of patients with minor injuries in emergency settings. Accid Emerg Nurs 2000;8(2):101-9.

7. DHS. Victorian Nurse Practitioner Project, Evaluation of sixteen Phase 2 demonstration projects. Melbourne: Victorian Department of Human Services; 2004.

8. Tachakra S, Deboo P. Comparing performance of ENPs and SHOs. Emerg Nurse 2001;9(7):36-9.

9. Tye CC, Ross FM. Blurring boundaries: Professional perspectives of the emergency nurse practitioner role in a major accident and emergency department. J Adv Nurs 2000;31(5): 1089-96.

10. Brown MA, Draye MA. Experiences of pioneer Nurse Practitioners in establishing advanced practice roles. J Nurs Scholarship 2003;35(4):391-7.

11. Cummings GG, Fraser K, Tarlier DS. Implementing advanced nurse practitioner roles in acute care: An evaluation of organizational change. J Nurs Administration 2003;33(3):139-45.

12. DiCenso, A., Matthews, M. Report on the Integration of Primary Health Care Nurse Practitioners into the Province of Ontario. 2005 [cited April 1, 2006]; Available from: http://www.health.gov.on.ca/english/public/pub/ministry reports/nurseprac03/exec_summ.pdf.

13. Keyzer DM. Working together: the advanced rural nurse practitioner and the rural doctor. Aust $J$ Rural Health 1997;5(4):184-9.

14. Neale J. Nurse practitioners and physicians: a collaborative practice. Clin Nurse Spec 1999;13(5):252-8.

15. Proctor S. The Developing Role of the Emergency Nurse Practitioner in a multi-professional context: A comparison of impact on patients of nurse to doctor, doctor to doctor referal. (RCAE267); 2003 [cited April 1, 2006]. Available from: http:/ / www.ReFeR.nhs.uk/ViewRecord.asp?ID=1147.

16. Williams A, Sibbald B. Changing roles and identities in primary health care: Exploring a culture of uncertainty. $J$ Adv Nurs 1999;29(3):737-45.

17. Wilson A, Pearson D, Hassey A. Barriers to developing the nurse practitioner role in primary care-The GP perspective. Family Practice 2002;19(6):641-6.

18. Appel AL, Malcolm P. The triumph and continuing struggle of nurse practitioners in New South Wales, Australia. Clin Nurse Spec 2002;16(4):203-10.

19. Duckett SJ. Interventions to facilitate health workforce restructure. Australia and New Zealand Health Policy 2005;2(1):14.

20. NH\&MRC. National Statement on Ethical Conduct in Research Involving Humans; 1999 [cited June 6, 2006]. Available from: http://www.nhmrc.gov.au/publications/synopses/e35syn.htm.

21. DHS. Human Research Ethics Committee; 2006 [cited March 31, 2006]. Available from: http://www.health.vic.gov. au/ethics/index.htm.

22. Lobiondo-Wood G, Haber J, editors. Nursing research: Methods, critical appraisal, and utilization. St. Louis, MI, USA: Mosby-Year Book; 1998.

23. O'Leary Z. Researching real-world problems: a guide to methods of inquiry. London: Sage Publications; 2005.

24. Polit DF, Beck CT. Nursing research: Principles and methods. 7th ed. Philadelphia: Lippincott Williams and Wilkins; 2004.

25. Parle JV, Ross NM, Doe WF. The medical care practitioner: Developing a physician assistant equivalent for the United Kingdom. Med J Aust 2006;185(1):13-7.

26. Gardner G. Issues in nurse practitioner developments in Australia. Cancer Forum 2004;28(3):132-4.

27. Considine J, Martin R, Smit D, Winter C, Jenkins J. Emergency nurse practitioner care and emergency department patient flow: Case-control study. Emerg Med Australasia 2006; 18(4):385-90. 